\title{
Delírio de infestação parasitária e transtorno bipolar: relato de caso
}

\author{
Delusional parasitosis and bipolar disorder: case report
}

\author{
Carlos Eduardo Leal Vidal ${ }^{1}$, Tábatha de Sousa Oliveira Barbosa ${ }^{2}$, Ariadny Rodrigues Nunes ${ }^{3}$, \\ Clarisse Silva Freitas Souza ${ }^{3}$
}

${ }^{1}$ Psiquiatra, Faculdade de Medicina de Barbacena, Barbacena, MG. ${ }^{2}$ Médica residente em Psiquiatria, Centro Hospitalar Psiquiátrico de Barbacena/Fundação Hospitalar do Estado de Minas Gerais, Barbacena, MG. ${ }^{3}$ Acadêmica de Medicina, Faculdade de Medicina de Barbacena.

\section{Resumo}

O presente relato tem por objetivo descrever o caso de uma paciente portadora de delírio de infestação parasitária comórbido com transtorno bipolar. Trata-se de paciente portadora de transtorno bipolar há mais de 30 anos e que se encontrava com quadro psíquico estabilizado e sem alterações do humor durante as consultas psiquiátricas. Em uma das suas avaliações periódicas, começou a se queixar da presença de vermes que estavam infestando seu corpo, o que já vinha ocorrendo há 8 anos. Estava em uso de carbonato de lítio e não aceitou tomar o antipsicótico prescrito porque já experimentara efeito colateral com essa classe de medicamentos. A associação entre delírio de infestação parasitária e transtorno bipolar é rara, e os autores encontraram apenas um caso semelhante descrito na literatura médica internacional.

Descritores: Transtorno delirante, síndrome de Ekbom, transtorno bipolar.

\begin{abstract} Keywords: Delusional disorder, Ekbom's syndrome, bipolar disorder.

\section{Introdução}

O delírio de infestação parasitária, também conhecido como síndrome de Ekbom, é uma síndrome psiquiátrica na qual o paciente apresenta uma crença delirante de que sua pele está infestada por insetos, vermes ou outros pequenos animais ${ }^{1-3}$. O início do quadro é insidioso e o delírio tipicamente é precedido por sensações táteis primárias, como prurido ou parestesia, ou mesmo alucinações, as quais precipitam o delírio secundário de infestação4.
\end{abstract}

The objective of the present report is to describe the case of a patient with delusional parasitosis comorbid with bipolar disorder. The patient had been diagnosed with bipolar disorder over 30 years ago and her mental state was stable without any mood disturbances detected during psychiatric visits. During one of her periodic evaluations, the patient started to complain that worms were infesting her body, which had been occurring for the past 8 years. She was taking lithium carbonate and refused to use an antipsychotic because she had experienced side effects after using this class of drugs. The association between delusional parasitosis and bipolar disorder is rare, and we found only one similar case described in the literature.

Na tentativa de eliminar os animais por extração mecânica ou por meio de pesticidas, o paciente pode provocar lesão e irritação local, o que confirma sua crença de que existe alguma coisa errada com sua pele ${ }^{3}$. As descrições muitas vezes são tão pormenorizadas que sugerem alucinações visuais. As lesões de pele, existentes na maioria dos casos, surgem tipicamente nas regiões corporais mais facilmente alcançadas pelas mãos ${ }^{3}$ e são exibidas como se fossem provas da infestação. É comum o paciente chegar à consulta apresentando tecido descamativo, cabelo ou o próprio "parasita" dentro de um recipiente

\section{Correspondência:}

Carlos Eduardo Leal Vidal, Rua Professor Vasconcelos, 467, Bairro Andorinhas, CEP 36205-238, Barbacena, MG. Tel.: (32) 3331.4106. E-mail: celv@uol.com.br Não há conflitos de interesse associados à publicação deste artigo. 
(caixa, vidro ou saco plástico). Tal fenômeno, conhecido como sinal da caixa de fósforos, é patognomônico, mas não obrigatório, e ocorre em torno de $30 \%$ dos $\operatorname{casos}^{2,3,5}$.

O primeiro caso documentado foi descrito por Thibierge em 1884, que utilizou o termo acarofobia para designar a síndrome. Outros termos empregados foram dermatofobia, parasitofobia e entomofobia. Em 1938, Ekbom descreveu oito casos de delírio de infestação utilizando o termo dermatozoenwhan para designá-los ${ }^{3,6}$.

O delírio de infestação parasitária é mais prevalente acima dos 50 anos de idade, e as mulheres são mais afetadas que os homens ${ }^{3}$. Em $15 \%$ dos casos, o delírio de infestação parasitária é compartilhado com mais de uma pessoa (folie a deux ou trois), geralmente residentes em uma mesma moradia ${ }^{3,7}$.

O diagnóstico do delírio de infestação parasitária é feito com base na história clínica, mas é importante considerar a existência de escabiose, doença de Grover, foliculite crônica e reação alérgica a picada de insetos no diagnóstico diferencial. Deve-se excluir também outros transtornos psiquiátricos, condições médicas com alteração da sensibilidade, uso de substâncias ou medicamentos ou abstinência de álcool ou cocaína $^{2}$. Embora o delírio de infestação parasitária seja reconhecido como um transtorno mental, os pacientes comumente procuram ajuda de um dermatologista ou clínico geral, e quase sempre rejeitam o encaminhamento para um psiquiatra ${ }^{3,4}$.

Neste artigo, os autores apresentam um caso clínico de delírio de infestação parasitária em paciente portadora de transtorno afetivo bipolar, inédito na literatura brasileira.

\section{Descrição do caso}

Paciente com 66 anos de idade, sexo feminino, viúva, profissional de nível superior da área da saúde, aposentada, branca, católica.

A paciente procurou o ambulatório de psiquiatria da Faculdade de Medicina de Barbacena em maio de 2006, a fim de dar continuidade a tratamento iniciado em Belo Horizonte há mais de 30 anos. Disse ser portadora de transtorno bipolar e fazer uso de carbonato de lítio ( $900 \mathrm{mg} / \mathrm{dia})$, clonazepam (2 $\mathrm{mg} /$ dia) e clorpromazina $100 \mathrm{mg} / \mathrm{dia}$, iniciados depois de uma internação psiquiátrica em 1989. Relatou já ter tomado outros medicamentos antes da hospitalização. Apresentou-se ao exame com bom aspecto geral, funções cognitivas preservadas, humor estável e sem sintomas psicóticos. Fala fluente, comunicativa e informando bem. A medicação foi mantida, e foram agendados retornos periódicos com intervalo bimensal. Não apresentou queixas ou alterações nas consultas subsequentes até março de 2007, quando começou a cismar com uma vizinha, dizendo que ela havia roubado seu dinheiro. Estava um pouco excitada ao relatar suas queixas, mas sem outros sintomas sugestivos de quadro maníaco. Manteve-se a mesma medicação, e não houve progressão do quadro. Em novembro do mesmo ano compareceu ao ambulatório mais falante que o habitual, com humor irritável e ideação persecutória. Foi prescrito trifluorperazina $5 \mathrm{mg}$, retirado no mês seguinte devido ao surgimento de sintomas extrapiramidais e por ter apresentado melhora dos sintomas delirantes. Retornou ao ambulatório em abril de 2008, quando se queixou de vermes na região anal, dizendo que não se tratava nem de oxiúro nem de áscaris, termos que ela conhecia. Ao ser inquirida sobre os supostos vermes, disse que foi contaminada há 8 anos ao desentupir uma rede de esgoto doméstico com suas próprias mãos, o que fez surgir "uma ferida na nuca", diagnosticada por dermatologista como um "molusco contagioso". Foi tratada com albendazol, betametasona creme e loratadina, mas não obteve melhora do quadro. Algum tempo depois, ao coçar a lesão percebeu que "os moluscos começaram a se reproduzir embaixo da unha", e que eles possuíam "alto grau de metamorfose, podendo ficar disfarçados de pele ou cutícula e roerem as unhas". Afirma que os moluscos atualmente se alojam na região sacral, mas só incomodam quando fica nervosa, cansada ou irritada. Mostra as mãos e aponta pequenos ferimentos que diz serem causados pelos vermes. Relata que os moluscos não penetram na sua vagina, "possivelmente por causa do pH ácido".

Histórico familiar. Pais e irmãos falecidos. Sem história familiar de interesse psiquiátrico. Teve pouco contato com os pais na infância e morou em uma creche até os 9 anos de idade. Não informa os motivos.

Histórico psiquiátrico. Refere uma internação psiquiátrica. Diz que durante suas crises ficava alegre, falante, com muita vontade de trabalhar e sem sono: "uma vez uma médica tirou minha medicação, passou maprotilina e eu tive outra crise de agitação". Fez três curetagens uterinas.

Exame físico. Presença de escoriações em ambas as mãos, principalmente nas extremidades dos dedos e sob as unhas. Sem lesões aparentes na região sacral.

Como terapêutica, prescreveu-se risperidona $1 \mathrm{mg}$, mas a paciente recusou-se a fazer uso, argumentando que teve efeito colateral com outro antipsicótico prescrito, e que esse problema não era de natureza psiquiátrica. A paciente continua em tratamento ambulatorial e persiste com a crença de que está infestada por vermes.

\section{Discussão}

De acordo com Alonso-Fernandez ${ }^{8}$, o delírio dermatozoico é um quadro inespecífico sem uma filiação psicopatológica e nosológica própria. Para ele, o transtorno psicopatológico básico, seja uma alucinose tátil crônica, delírio demencial ou um delírio primário ou depressivo, corresponderia, respectivamente, a quatro categorias nosológicas: psicoses sintomáticas, psicose orgânica, esquizofrenia e depressão vital.

Munro ${ }^{9}$ classificou o delírio de parasitose como um tipo de psicose hipocondríaca monossintomática, caracterizando a síndrome como "um sistema delirante hipocondríaco isolado e relativamente distinto do restante da personalidade". Segundo o mesmo autor, o delírio pode ser acompanhado tanto por alterações perceptivas como ilusões ou alucinações. 
Outros modelos abordam o delírio parasitário como uma manifestação possível de diferentes padrões de apresentação psiquiátrica, como psicoses afetivas, psicoses orgânicas e psicoses agudas e confusionais associadas ao consumo abusivo de álcool e a transtornos delirantes crônicos. Do ponto de vista etiológico, o transtorno pode surgir como um sintoma inespecífico, que deve ser abordado dentro de uma formulação diagnóstica individual e multidimensional. Por outro lado, o sintoma pode ser manifestação de um transtorno psiquiátrico primário ou decorrente de problema clínico ${ }^{6}$.

Assim, o delírio de infestação parasitária pode ser primário ou secundário. Quando primário, o delírio surge espontaneamente e preenche os critérios diagnósticos para transtorno delirante persistente. No delírio de infestação parasitária secundário, existe uma condição clínica, neurológica ou psiquiátrica subjacente. As mais comuns são esquizofrenia, demência, depressão, diabetes, neuropatias e acidentes cardiovasculares, mas muitas outras condições mórbidas podem estar associadas. O delírio de infestação parasitária também pode ocorrer como consequência de intoxicação por drogas (anfetaminas ou cocaína) e também como efeito colateral de medicamentos. Uma classificação etiológica abrangente pode ser encontrada em Lepping \& Freundenmann ${ }^{10}$.

Com relação aos aspectos psicopatológicos, não está claro se o transtorno primário é uma alucinação tátil ou uma ilusão (ou mesmo uma sensação real) com uma interpretação delirante subsequente, ou se esse quadro é fundamentalmente de origem delirante ${ }^{6}$. De acordo com Berrios ${ }^{11}$, na prática clínica, as alucinações táteis são quase sempre associadas a interpretações delirantes.

Em 1978, Skott ${ }^{12}$ relatou os achados de 57 pacientes, salientando que os quadros de delírio de infestação acometiam pacientes mais velhos, com idade média de 64 anos, predominavam no sexo feminino (42 mulheres para 15 homens) e os sintomas tinham a duração média de 4 anos antes de se estabelecer o diagnóstico. Entre os pacientes estudados, foram encontrados os seguintes diagnósticos: transtorno mental orgânico como demência ou diabetes $(42 \%)$, paranoia $(28 \%)$, folie a deux (25\%), retardo mental (14\%) e depressão (12\%).

Traber ${ }^{13}$ fez uma extensa revisão que incluiu 1.223 casos de delírio de infestação parasitária. Desse total, descreveu as categorias diagnósticas de 449 casos, que foram assim distribuídas: delírio de infestação "puro", 40,3\%; psicoses orgânicas, 21,8\%; psicose induzida, 14,4\%; esquizofrenia, $10,6 \%$; psicoses afetivas, $9,1 \%$; e neuroses, $3,5 \%$.

O presente caso revela uma paciente com síndrome de Ekbom cujo perfil se aproxima muito do padrão encontrado na literatura: sexo feminino, mais de 50 anos, isolamento social e viuvez. A exceção é feita para o grau de escolaridade, que tende a ser baixo nessas pacientes. Outra peculiaridade do quadro, e dessa paciente, é a resistência em utilizar antipsicóticos, já que acredita possuir uma doença dermatológica.

Nessa paciente, o surgimento do delírio vários anos depois do diagnóstico do transtorno afetivo e a persistência de tal delírio, mesmo na ausência de transtorno do humor, sugerem tratar-se de um delírio primário comórbido ao transtorno bipolar. O termo comorbidade é empregado aqui para se referir à ocorrência de dois transtornos em um mesmo paciente, independente de esses transtornos terem mesmo substrato etiológico ou compartilharem mesmo mecanismo psicopatológico.

A história pregressa e evolutiva associada ao exame psíquico atual indica que a paciente seja portadora de transtorno delirante persistente, tipo hipocondríaco, e transtorno afetivo bipolar. Na revisão realizada pelos autores, verificaram-se várias referências a delírio de parasitose relacionado aos transtornos depressivos ${ }^{12,14,15}$ e apenas um caso de delírio de infestação associado ao transtorno bipolar ${ }^{16}$.

\section{Referências}

1. Lepping P, Russell I, Freudenmann RW. Antipsychotic treatment of primary delusional parasitosis: systematic review. Br J Psychiatry. 2007;191:198-205.

2. Lee CS. Delusions of parasitosis. Dermatol Ther. 2008;21(1):2-7.

3. Goi PD, Scharlau CT. Síndrome de Ekbom acompanhada de automutilação. Rev Psiquiatr RS. 2007;29(1):97-9.

4. Le L, Gonski PN. Delusional parasitosis mimicking cutaneous infestation in elderly patients. Med J Aust. 2003;179(4):209-10.

5. Amâncio EJ, Peluso CM, Santos ACG, Magalhäes, CCP, Pires MFC, Peña Dias AP, et al. Síndrome de Ekbom e torcicolo espasmódico: relato de caso. Arq Neuropsiquiatr. 2002;60(1):155-8.

6. Vidal Castro C, Rejón Altable C, Sierra Acin AC. Percepción y pensamiento en los delirios de infestación. Actas Esp Psiquiatr. 2006;34(2):140-3.

7. Cordeiro Jr. Q, Corbett CEP. Delírio de infestação parasitária e folie a deux: relato de caso. Arq Neuro-Psiquiatr. 2003; 61(3B):872-5.

8. Alonso-Fernandez F. Fundamentos de la Psiquiatria Actual. vol. II. $3^{\text {a }}$ ed. Madri: Paz Montalvo; 1977.

9. Munro A. Monosymptomatic hypochondriacal psychosis. Br J Psychiatry Suppl. 1988;(2):37-40.

10. Lepping P, Freudenmann RW. Delusional parasitosis: a new pathway for diagnosis and treatment. Clin Experiment Dermatol. 2007;33(2):113-7.

11. Berrios GE. Tactile hallucinations: conceptual and historical aspects. J Neurol Neurosurg Psychiatry. 1982;45(4):285-93.

12. Skott A. Delusions of infestation. Reports From the Psychiatric Research Center, No. 13. Goteborg: St. Jorgen's Hospital; 1978.

13. Trabert W. 100 years of delusional parasitosis. Meta-analysis of 1,223 case reports. Psychopathology. 1995;28(5):238-46.

14. Nicolato R, Corrêa H, Romano-Silva MA, Teixeira AL Jr. Delusional parasitosis or Ekbom syndrome: a case series. Gen Hosp Psychiatry. 2006;28(1):85-7.

15. Slaughter JR, Zanol K, Rezvani H, Flax J. Psychogenic parasitosis A case series and literature review. Psychosomatics. 1998;39(6):491-500.

16. Even C, Goeb JL, Dardennes R. [Bipolar affective disorder and Ekbom syndrome: apropos of a case]. Encephale. 1997;23(5):397-9. 